\title{
IGF-1-induced MMP-11 expression promotes the proliferation and invasion of gastric cancer cells through the JAK1/STAT3 signaling pathway
}

\author{
CHAO SU ${ }^{1,2}$, WENCHANG WANG ${ }^{2}$ and CUNCHUAN WANG ${ }^{1}$ \\ ${ }^{1}$ Department of Gastrointestinal Surgery, The First Affiliated Hospital of Jinan University, Guangzhou, Guangdong 510630; \\ ${ }^{2}$ Department of Gastrointestinal Surgery, The Municipal Hospital of Weihai, Weihai, Shandong 264200, P.R. China
}

Received February 26, 2016; Accepted August 23, 2017

DOI: $10.3892 / \mathrm{ol} .2018 .8234$

\begin{abstract}
The present study aimed to investigate the association between insulin-like growth factor-1 (IGF-1) and matrix metalloproteinase-11 (MMP-11) expression in gastric cancer (GC) and the underlying mechanisms in SGC-7901 cells. Reverse transcription-quantitative polymerase chain reaction analysis revealed that the expression of IGF-1 and MMP-11 was significantly upregulated in GC tissues compared with normal gastric tissue. Furthermore, IGF-1 significantly and dose-dependently promoted MMP-11. Western blotting revealed that the addition of IGF-1 to SGC-7901 cells led to an evident enhancement in signal transducer and activator of transcription 3 (STAT3), IGF-1R and Janus kinase 1 (JAK1) phosphorylation at 20 and $40 \mathrm{~min}$. A decrease in the extent of the elevated expression of MMP-11 and the enhanced phosphorylation of STAT3, JAK1 and IGF-1 receptor (IGF-1R) induced by IGF-1 in SGC-7901 cells were observed following treatment with NT157 (an IGF-1R inhibitor). Furthermore, piceatannol (a JAK1 inhibitor) or small interfering RNA against STAT3 reduced the extent of the increased expression of MMP-11 induced by IGF-1 in SGC-7901 cells. Piceatannol treatment induced the dose-dependent decline in the enhancement of STAT3 phosphorylation induced by IGF-1, indicating that the JAK1/STAT3 pathway may be implicated in the elevated expression of MMP-11 induced by IGF-1 in SGC-7901 cells. Finally, IGF-1 treatment significantly promoted the proliferation and invasion of SGC-7901 cells, which was inhibited following NT157, piceatannol or si-STAT3 treatment. The present study therefore demonstrated that IGF-1-induced
\end{abstract}

Correspondence to: Dr Chao Su, Department of Gastrointestinal Surgery, The First Affiliated Hospital of Jinan University, 613 Huangpu Road, Guangzhou, Guangdong 510630, P.R. China E-mail: chaosu_cn@163.com

Key words: gastric cancer, insulin-like growth factor-1, SGC-7901 cells, matrix metalloproteinase-11, Janus kinase 1/signal transducer and activator of transcription 3 pathway
MMP-11 may have facilitated the proliferation and invasion of SGC-7901 cells via the JAK1/STAT3 pathway.

\section{Introduction}

Gastric cancer (GC), often diagnosed at advanced stage, is the second-leading cause of cancer-associated mortality worldwide, although its incidence has been substantially declining for the past decades $(1,2)$. GC frequently invades the surrounding tissues to spread cancer cells, leading to high mortality rates for patients suffering from GC (3); understanding the molecular mechanisms of GC invasion and metastasis, including the alterations to metastasis-associated genes, oncogenes, and tumor suppressor genes, may inform potential treatment avenues for patients with GC (4-6). Investigating the molecular mechanisms underlying GC invasion and metastasis, and identifying novel biomarkers involved in GC invasion, has been a focus for cancer research (7-9), but has proven difficult thus far.

Matrix metalloproteinases (MMPs) mediate the degradation of the extracellular matrix to affect tumor cell adhesion and migration. MMPs are upregulated in numerous types of cancer, and their expression is closely associated with the occurrence, invasion and prognosis of cancer $(10,11)$; previous studies have demonstrated that the increased expression of MMPs is associated with the enhanced invasiveness of GC cells, and is associated with poor prognosis in patients with GC (12-14). MMP-11 has been revealed to have a crucial role in the proliferation and invasion of GC, and its expression is associated with the expression of insulin-like growth factor-1 (IGF-1), indicating the presence of a possible association between MMP-11 and IGF-1 in the development and progression of GC $(15,16)$. IGF-1 may stimulate a range of biological processes, including cellular proliferation, differentiation, migration and survival, by binding to the IGF-1 receptor (IGF-1R) (17-19). The altered expression of IGF-1 has been reported in certain tumor types, including in liver and breast cancer, and GC (20-22); however, the specific mechanisms associated with IGF-1 dysregulation have not yet been fully characterized. A recent study demonstrated that IGF-1R knockdown not only suppressed the growth of GC cells via G1 cell cycle arrest and apoptosis, but also inhibited cancer cell 
invasion (23). Therefore, in the present study, the expression of IGF-1 and MMP-11 in GC tissues was analyzed, and the specific mechanism underlying GC proliferation and invasion associated with IGF-1 was investigated.

\section{Materials and methods}

Reagents. Recombinant human IGF-1 $(25,50,100 \mathrm{ng} / \mathrm{ml})$, NT157 $(5,10 \mu \mathrm{M})$ and piceatannol $(10,20 \mu \mathrm{M})$ were all obtained from Sigma-Aldrich; Merck KGaA (Darmstadt, Germany). Different doses of IGF-1 were employed Antibodies against phospho (p)-STAT3 (sc-8059), p-JAK1 (sc-16773), p-JAK2 (sc-21870), p-JAK3 (sc-16567), p-IGFR (sc-81499), $\beta$-actin (sc-47778), horseradish peroxidase (HRP) coupled goat anti-mouse IgG (sc-2031) and HRP coupled rabbit anti-goat IgG (sc-2768) secondary antibodies were all purchased from Santa Cruz Biotechnology, Inc.

Clinical specimens. From September 2008 to November 2011, Specimens of GC tissue (male 7, female 3, 58 $\pm 13.5, \mathrm{n}=10$ ), para-carcinoma tissue (male 7 , female $3,58 \pm 13.5, n=10$ ), normal gastric tissue (male 7 , female $3,58 \pm 13.5, \mathrm{n}=10$ ), and gastric ulcer tissue (male 8 , female $2,55.3 \pm 15.6, \mathrm{n}=10$ ) were collected from the Department of Gastrointestinal Surgery in Renji Hospital (Shanghai, China). The present study was approved by the Institutional Research Ethics Committee of Renji Hospital. Written informed consent was obtained from all participants for the use of tissue samples. None of the patients recruited to the present study had received other anticancer treatments prior to surgery. Sections from each specimen were independently examined by two pathologists, and histological typing was performed using Lauren's classification (24). Tumor, node and metastasis classification of malignant tumors was assigned in accordance to the International Union Against Cancer (25).

Cells lines and culture. The human GC SGC-7901 cell line was obtained from the American Type Culture Collection (Manassas, VA, USA). Cells were maintained in RPMI-1640 medium (Invitrogen; Thermo Fisher Scientific, Inc., USA) supplemented with $10 \%$ fetal bovine serum (FBS, Sigma-Aldrich; Merck KGaA) and $100 \mathrm{U} / \mathrm{ml}$ of penicillin/streptomycin (Sigma-Aldrich; Merck KGaA) at $37^{\circ} \mathrm{C}$ in a humidified atmosphere with $5 \% \mathrm{CO}_{2}$. SGC-7901 cells at logarithmic phase were cultured with different doses of IGF-1, NT157 or piceatannol for different time (20,40, and $60 \mathrm{~min}$ ). The Stat 3 siRNA or Scramble siRNA was transfected into SGC-7901 cells using Lipofectamine 2000 (Invitrogen; Thermo Fisher Scientific, Inc.). Stat3 siRNA: sense: 5'-CAC CGCAACAGATTGCCTGCATTGGTTCTGCAGGCAATC TGTTGCTTTTTTG-3'; antisense: 5'-GATCCAAAAAAG CAACAGATTGCCTGCATTGGTCTCTTGAACCAATGC AGGCAATCTGTTGC-3'; Scramble siRNA: sense: 5'-CAC CGTTCTCCGAACGTGTCACGTCAAGAGATTACGTGA CACGTTCGGAGAATTTTTTG-3'; antisense: 5'-GATCCA AAAAATTCTCCGAACGTGTCACGTAATCTCTTGACG TGACACGTTCGGAGAAC-3'.

RNA isolation and reverse transcription-quantitative polymerase chain reaction $(R T-q P C R)$. RT-qPCR was performed as reported previously (26), with modifications. Briefly, total RNA was extracted from cells using TRIzol reagent (Invitrogen; Thermo Fisher Scientific, Inc.) and refined using an RNeasy Mini kit (Qiagen, Inc., Valencia, CA, USA) according to the manufacturers' protocols. Samples (1 $\mu \mathrm{g}$ RNA) were reverse-transcribed using a first-strand cDNA synthesis kit (Invitrogen; Thermo Fisher Scientific, Inc.). The synthesized cDNA was used for qPCR with the Chromo 4 instrument and SsoFast ${ }^{\mathrm{TM}}$ EvaGreen Supermix, and then analyzed with Opticon Monitor Analysis software version 2.0 (all Bio-Rad Laboratories, Inc., Hercules, CA, USA). Primers used for amplification were as follows: IGF-1 sense: 5'-CAACAAGCCCACAGGGTATGGC-3'; antisense: 5'-ACAGGTAACTCGTGCAGAGCAAAGC-3'; MMP-1 sense: 5'-ACATCGTGTTGCGGCTCATGA-3'; antisense: 5'-TTT GGGGTTTGTGGGCCGATGG-3'; GAPDH sense: 5'-GTG GACATCCGCAAAGAC-3'; antisense: 5'-AAAGGGTGTAAC GCAACTAA-3'. The PCR cycle included an initial denaturation at $95^{\circ} \mathrm{C}$ for $10 \mathrm{~min}$ followed by 40 cycles of $95^{\circ} \mathrm{C}$ for $15 \mathrm{sec}$, and $60^{\circ} \mathrm{C}$ for $1 \mathrm{~min}$. Specificity was determined by electrophoretic analysis of the reaction products. GAPDH was used as an internal standard. Data were analyzed using the $2^{-\Delta \Delta C T}$ method as described elsewhere (27).

Western blotting. Western blotting was performed as previously described (28), with modifications. SGC-7901 cells were harvested in radioimmunoprecipitation assay lysis buffer (Bioteke Corporation, Beijing, China) and $35 \mu \mathrm{g}$ protein per lane was separated by $10 \%$ SDS-PAGE mini-gel and transferred to a polyvinylidene fluoride membrane (EMD Millipore, Billerica, MA, USA) for $60 \mathrm{~min}$ at $100 \mathrm{~V}$. Following incubation in blocking buffer (Tris-buffered saline containing 5\% non-fat dry milk, $150 \mathrm{mM} \mathrm{NaCl}, 50 \mathrm{nM}$ Tris, $0.05 \%$ Tween-20, $\mathrm{pH}$ 7.5) for $1 \mathrm{~h}$ at room temperature, the membrane was hybridized in blocking buffer with the aforementioned primary antibodies against p-STAT3 (1:200), p-IGF-1R (1:500), p-JAK1 (1:200), p-JAK2 (1:500), p-JAK3 (1:200), and $\beta$-actin (1:500) overnight at $4^{\circ} \mathrm{C}$, then incubated with HRP coupled goat anti-mouse IgG $(1: 3,000)$ or rabbit anti-goat IgG $(1: 5,000)$ secondary antibodies followed by detection with an enhanced chemiluminescence reagent (GE Healthcare, Chicago, IL, USA). The band densities were analyzed with ImageJ software (version 1.47, National Institutes of Health, Bethesda, MD, USA).

Cell proliferation and invasion assays. Cell proliferation and invasion analyses were performed as previously described (29), with alterations. The proliferation ability of SGC-7901 cells was assessed by an MTT spectrophotometric dye (Sigma-Aldrich; Merck KGaA) assay. SGC-7901 cells were seeded in 24-well plates at a density of $8 \times 10^{3}$ cells per well. The proliferation rate was measured at $0,24,48,72,96,120$ and $144 \mathrm{~h}$ after seeding. Cells were incubated for $4 \mathrm{~h}$ in $20 \mu \mathrm{l} \mathrm{MTT}$ at $37^{\circ} \mathrm{C}$, and the supernatant was removed. MTT was dissolved by adding $150 \mu \mathrm{l} /$ well dimethylsulfoxide. The absorbance was determined at $450 \mathrm{~nm}$ using a microplate reader.

For cell invasion analysis, transwell chambers (24-well; pore size, $8 \mu \mathrm{m}$; BD Biosciences, San Jose, CA, USA) were coated with Matrigel (BD Biosciences) prior to adding the cells $\left(5 \times 10^{5}\right.$ cells $\left./ \mathrm{ml}\right)$ and incubated at $37^{\circ} \mathrm{C}$ for $24 \mathrm{~h}$, allowing the gel to solidify. RPMI 1640 with $10 \%$ FBS $(400 \mu \mathrm{l})$ was added to the lower chamber to act as the chemotactic agent. 

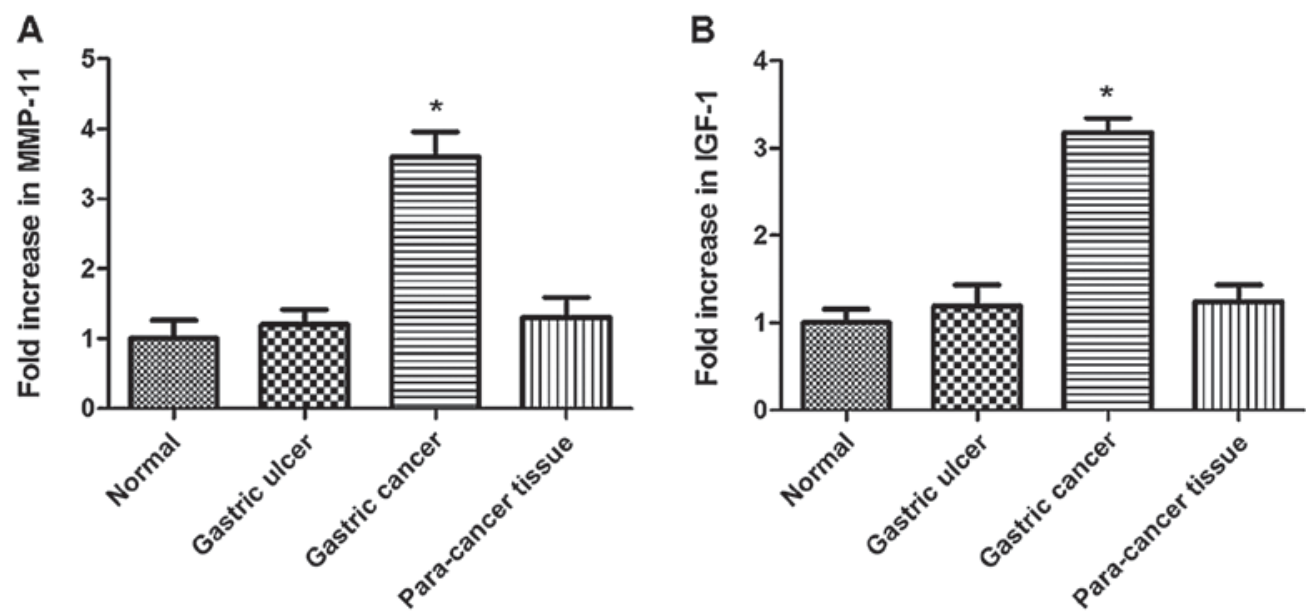

Figure 1. The expression of (A) MMP-11 and (B) IGF-1 in gastric cancer tissues, normal tissues, gastric ulcer tissues, and para-carcinoma tissues, respectively. Reverse transcription-quantitative polymerase chain reaction analysis was performed to measure the fold increase in MMP-11 and IGF-1. GAPDH was used as the internal control. "P<0.05 vs. normal gastric tissue. MMP-11, matrix metalloproteinase-11; IGF-1, insulin-like growth factor-1.

Invasive cells on the lower side were fixed with cold methanol $\left(-20^{\circ} \mathrm{C}\right)$ for $10 \mathrm{~min}$ and then air-dried. Cells were stained with $0.1 \%$ crystal violet (dissolved in methanol) for $30 \mathrm{~min}$ at room temperature, and then counted using a brightfield microscope at a magnification of $\mathrm{x} 200$.

Statistical analysis. All experiments were performed at least three times. Statistical analyses were performed using GraphPad Prism 6 software (GraphPad Software Inc., La Jolla, CA, USA). A one-way analysis of variance was performed to determine the differences between multiple groups followed by the Tukey's test. Data were presented as the mean \pm standard error of the mean. $\mathrm{P}<0.05$ was considered to indicate a statistically significant difference.

\section{Results}

Expression of MMP-11 and IGF-1 is significantly upregulated in GC tissues. The expression of MMP-11 and IGF-1 was determined in GC, normal gastric, gastric ulcer and para-carcinoma tissue samples using RT-qPCR. The expression of MMP-11 did not differ significantly between normal, gastric ulcer and para-carcinoma tissue samples, whereas it was significantly higher in GC tissues (Fig. 1A; $\mathrm{P}<0.05$ ). Fig. 1B illustrates the differences in IGF-1 expression between the four groups. Similarly, no significant alterations to IGF-1 expression were observed between normal gastric, gastric ulcer and para-carcinoma tissue samples, whereas GC tissues exhibited significantly higher expression of IGF-1 $(\mathrm{P}<0.05)$.

IGF-1 elevates the phosphorylation of STAT3, JAK1, and $I G F-1 R$ in SGC-7901 cells. Next, the association between IGF-1 and MMP-11 expression in SGC-7901 cells was examined. IGF-1 treatment significantly promoted MMP-11 expression in SGC-7901 cells in parallel with increases in the dose of IGF-1 ( $<<0.05$; Fig. 2A). Given as the JAK/STAT pathway may be activated in response to a variety of cytokines and growth factors, including epidermal growth factor, interleukin-6 and platelet-derived growth factor (30), western blotting was performed to investigate the time-dependent action of IGF-1 on the phosphorylation of JAK family kinases and STAT3 in SGC-7901 cells. The addition of $50 \mathrm{ng} / \mathrm{ml} \mathrm{IGF-1}$ to SGC-7901 cells enhanced the phosphorylation of STAT3, JAK1 and IGF-1R at 20, 40 and $60 \mathrm{~min}$, although this was observed to a lesser extent at $60 \mathrm{~min}$ (Fig. 2B). By contrast, the phosphorylation of JAK2 and 3 was not affected following IGF-1 stimulation. These data indicated that STAT3 and JAK1, but not JAK2 and JAK3, were associated with the effect of IGF-1 signaling in SGC-7901 cells.

NT157 reduces the phosphorylation of STAT3, JAK1, and $I G F-1 R$ in SGC-7901 cells. Considering the role of IGF-1R in cell proliferation, differentiation, migration and survival following the binding of IGF-1, the IGF-1R inhibitor NT157 was utilized to examine the effect of IGF-1R on MMP-11 expression, and the phosphorylation of STAT3, JAK1 and IGF-1R in SGC-7901 cells. As demonstrated in Fig. 3A, NT157 treatment caused a significant decline in the elevated expression of MMP-11 induced by IGF-1 in SGC-7901 cells that was inversely associated with the concentration of NT157. In addition, the IGF-1-induced phosphorylation of STAT3, JAK1, and IGF-1R was also inhibited in SGC-7901 cells following NT157 treatment (5 $\mu \mathrm{M}$; Fig. 3B). The results in Fig. 3 indicated that the phosphorylation of STAT3, JAK1 and IGF-1R following IGF-1 treatment was induced by IGF-1R activity in SGC-7901 cells.

JAK1/STAT3 pathway is implicated in the elevated expression of MMP-11 elicited by IGF-1 in SGC-7901 cells. The present study has demonstrated that IGF-1 regulated MMP-11 expression and the phosphorylation of STAT3 and JAK1 in SGC-7901 cells; however, there is limited data regarding the association between IGF-1-induced MMP-11, STAT3 and JAK1 activation. The present study therefore examined the effects of STAT3 and JAK1 on the IGF-1-induced activation of MMP-11 in SGC-7901 cells using piceatannol (a JAK1 inhibitor) and small interfering RNA targeted at STAT3 (si-STAT3). As indicated by Fig. 4A, piceatannol treatment significantly decreased the elevated expression of MMP-11 induced by IGF-1 in SGC-7901 cells in a dose-dependent manner; 

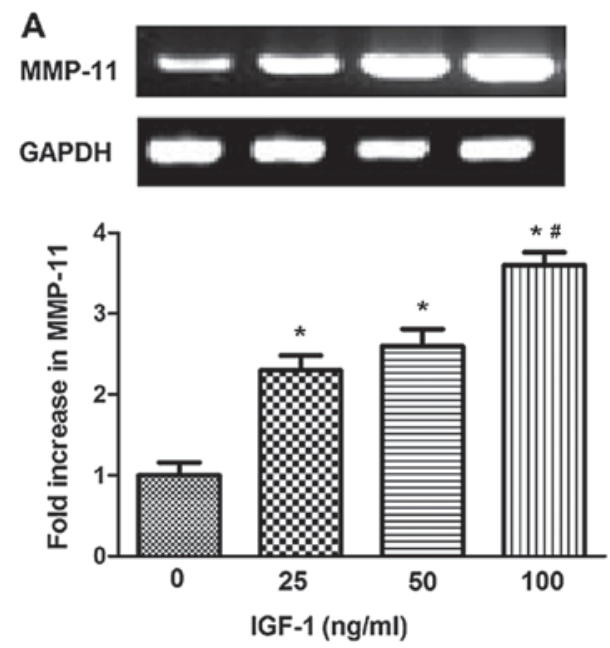

B

(min)

\begin{tabular}{llllll}
20 & \multicolumn{2}{c}{ Control } & & \multicolumn{3}{l}{ IGF-1 $(50 \mathrm{ng} / \mathrm{ml})$} \\
& 40 & 60 & 20 & $40 \quad 60$
\end{tabular}

p-STAT3

p-IGF-1R

p-JAK1

p-JAK2

p-JAK3

$\beta$-actin
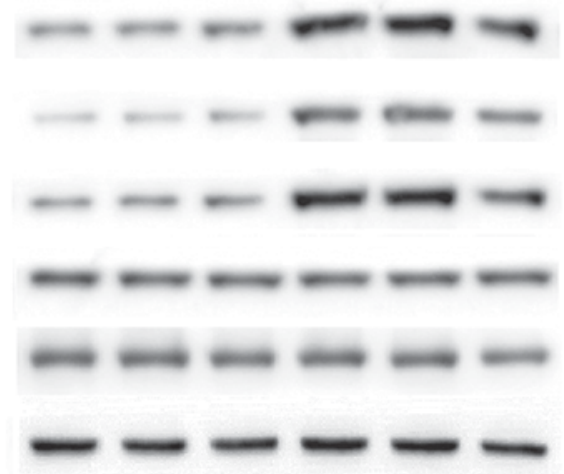

Figure 2. Effect of IGF-1 on (A) MMP-11 expression and (B) the JAK/STAT pathway in SGC-7901 cells. SGC-7901 cells were stimulated with IGF-1. Reverse transcription-quantitative polymerase chain reaction analysis was performed to detect the fold increase in MMP-11, and western blotting was performed to measure the phosphorylation of the JAK kinases, STAT3, and IGF-1R; $\beta$-actin was used as protein loading control. ${ }^{*} \mathrm{P}<0.05$ vs. no treatment; ${ }^{\#} \mathrm{P}<0.05$ vs. $25 \mathrm{ng} / \mathrm{ml}$ IGF-1. IGF-1, insulin-like growth factor-1; MMP-11, matrix metalloproteinase-11; JAK, Janus kinase; STAT, signal transducer and activator of transcription; IGF-1R, IGF-1 receptor.

A

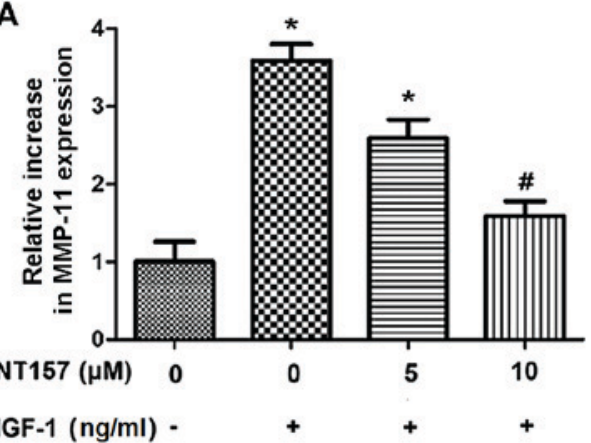

B

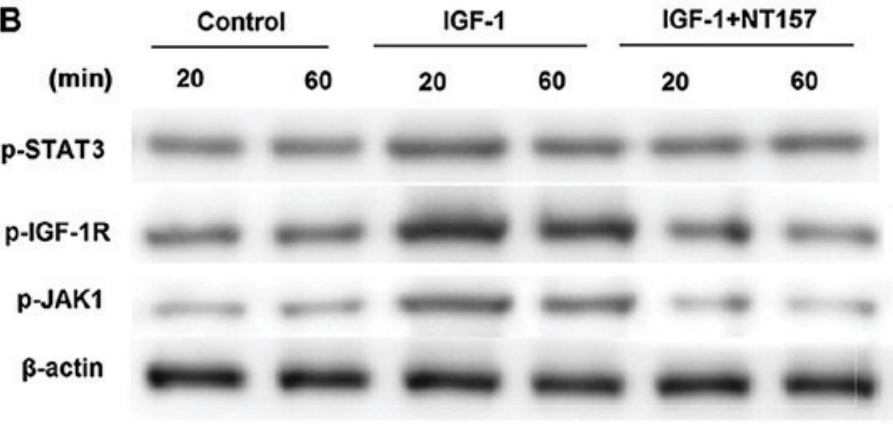

Figure 3. IGF-1R is implicated in the elevated expression of MMP-11 as well as the enhanced phosphorylation of STAT3, JAK1 and IGF-1R induced by IGF-1 in SGC-7901 cells. (A) NT157, an IGF-1R inhibitor, significantly reduced the extent that IGF-1 increased the expression of MMP-11 in SGC-7901 cells. Reverse transcription-quantitative polymerase chain reaction analysis was performed to detect the change in the expression of MMP-11; GAPDH was used as the internal control. (B) STAT3, JAK1, and IGF-1R phosphorylation induced by IGF-1 (50 ng/ml) was also inhibited in SGC-7901 cells following treatment with $5 \mu \mathrm{M}$ NT157. Western blotting was performed to measure the phosphorylation of JAK1, STAT3, and IGF-1R; $\beta$-actin was used as protein loading control. ${ }^{\text {} P} \mathrm{P}<0.05$ vs. no treatment. "P<0.05, vs. IGF-1 alone. IGF-1R, insulin-like growth factor-1 receptor; MMP-11, matrix metalloproteinase-11; STAT3, signal transducer and activator of transcription 3; JAK1, Janus kinase 1.

the maximal decline in MMP-11 expression was observed following STAT3-knockdown with si-STAT3. Furthermore, the enhanced phosphorylation of STAT3 induced by IGF-1 was reduced in SGC-7901 cells proportional to the concentration of piceatannol (Fig. 4B). These results demonstrate the association of the JAK1/STAT3 pathway with the increased expression of MMP-11 induced by IGF-1 in SGC-7901 cells.

IGF-1 promotes the proliferation and invasion of SGC-7901 cells via the JAK1/STAT3 pathway. The data of the present study have indicated the association of the JAK1/STAT3 pathway with the IGF-1-induced expression of MMP-11 in SGC-7901 cells; the role of MMP-11 in GC proliferation and invasion has been previously established (16). Thus, the present study next evaluated the proliferation and invasion of SGC-7901 cells following stimulation with IGF-1. IGF-1 treatment induced the proliferation and invasion of SGC-7901 cells; this effect was less pronounced following treatment with
NT157, piceatannol, or si-STAT3 (Fig. 5A and B). The data of Fig. 5 indicate that the IGF-1-induced expression of MMP-11 may promote the proliferation and invasion of SGC-7901 cells through the JAK1/STAT3 pathway.

\section{Discussion}

MMP-11 and IGF-1 have been demonstrated to be associated with the proliferation and invasion of GC $(15,16)$; however, the specifics of the interaction between these signaling pathways remain uncharacterized. Although the JAK/STAT pathway serves a role in the progression of $\mathrm{GC}$, the mechanism by which this pathway is associated with the IGF-1-induced proliferation and invasion of GC has not been identified. The present study demonstrated that the expression of IGF-1 and MMP-11 was significantly upregulated in GC tissue relative to normal gastric tissue. IGF-1 induced the expression of MMP-11, as well as the phosphorylation of STAT3, IGF-1R and 


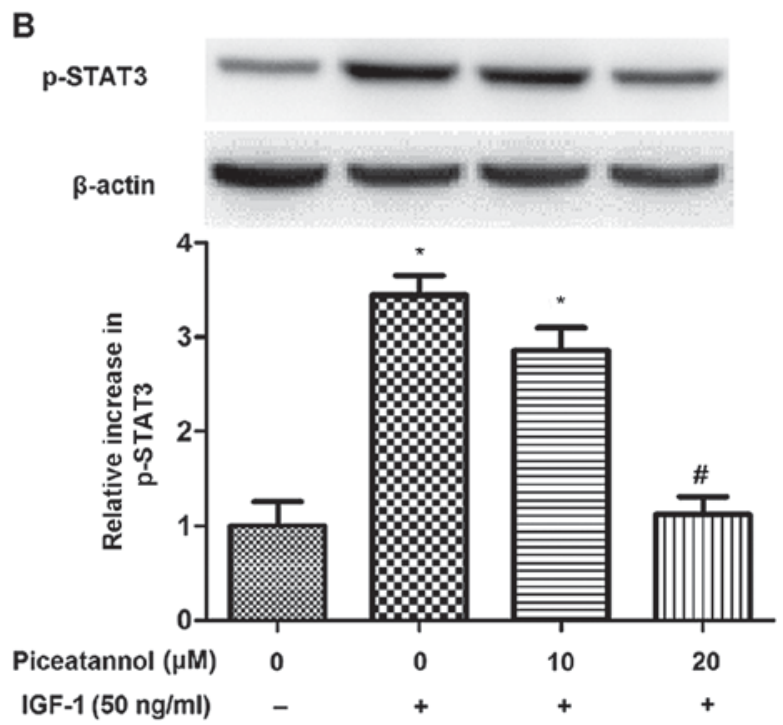

Figure 4. JAK1/STAT3 pathway is implicated in the increased expression of MMP-11 induced by IGF-1 treatment in SGC-7901 cells. (A) The JAK1 inhibitor piceatannol significantly reversed the elevated expression of MMP-11 induced by IGF-1 in SGC-7901 cells, proportional to the concentration of piceatannol; the maximal decline in MMP-11 expression was observed following si-STAT3 interference. Reverse transcription-quantitative polymerase chain reaction analysis was performed to detect the increase in MMP-11, GAPDH was used as the internal control. (B) Piceatannol stimulation led to a significant decline in the increase in STAT3 phosphorylation induced by IGF-1 in SGC-7901 cells. Western blotting was performed to measure the phosphorylation of STAT3; $\beta$-actin was used as a protein loading control. ${ }^{*} \mathrm{P}<0.05$ vs. no treatment; ${ }^{*} \mathrm{P}<0.05$ vs. IGF-1 alone. JAK1, Janus kinase 1 ; STAT3, signal transducer and activator of transcription 3; MMP-11, matrix metalloproteinase-11; IGF-1, insulin-like growth factor-1.

JAK1 in SGC-7901 cells. Treatment with an IGF-1R inhibitor reversed the enhanced phosphorylation of STAT3, JAK1 and IGF-1R induced by IGF-1 in SGC-7901 cells. In addition, the JAK1/STAT3 pathway was associated with the increased expression of MMP-11 induced by IGF-1 in SGC-7901 cells. Finally, the present study demonstrated that IGF-1-induced MMP-11 expression may have facilitated the proliferation and invasion of SGC-7901 cells via JAK1/STAT3 pathway.

Zhao et al (15) reported that the increased expression of MMP-11 was associated with an elevation in IGF-1 expression in GC tissues. Kou et al (16) reported that MMP-11 knockdown repressed the proliferative and invasive activities of SGC-7901 cells, with a corresponding decrease in the expression of IGF-1, PCNA and VEGF. The present study reported the increased expression of IGF-1 and MMP-11 in GC tissue compared with non-cancerous tissue, and that IGF-1 treatment induced MMP-11 expression in SGC-7901 cells. The data of the present study concerning IGF-1 and MMP-11 expression in GC tissues are consistent with a previous study (15).

The JAK/STAT pathway regulates cell development and survival. Giorgetti-Peraldi et al (31) identified that insulin promoted the tyrosine phosphorylation of JAK1 in fibroblasts overexpressing the insulin receptor, but did not alter the tyrosine phosphorylation status of JAK2. However, Saad et al (32) demonstrated that insulin stimulated the tyrosine phosphorylation of JAK2 in the insulin-sensitive tissues of rats. Subsequently, Gual et al (33) reported that in mouse fibroblast NIH 3T3 cells overexpressing insulin and IGF-1 receptors, treatment with insulin and IGF-1 resulted in the phosphorylation and activation of JAK1 and JAK2, with JAK1 interacting directly with phosphorylated insulin and IGF-1 receptors. Previous studies have also demonstrated that insulin stimulates the phosphorylation and activation of STAT1, 3 and $5(34,35)$. The importance of the JAK/STAT3 pathway in the

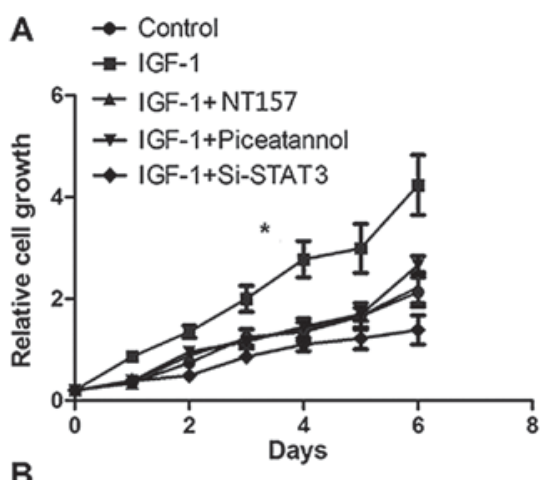

B

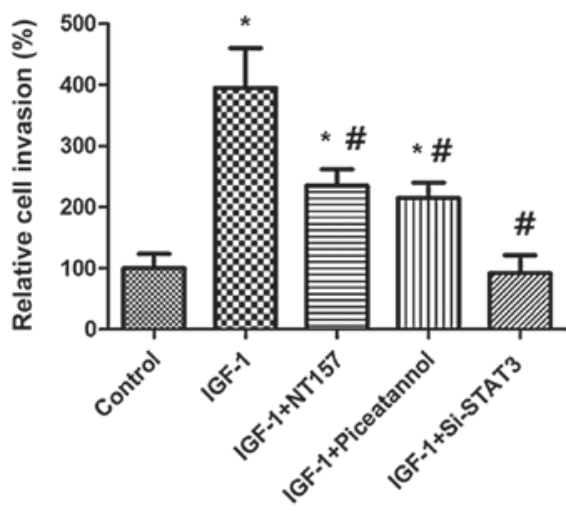

Figure 5. IGF-1 promotes (A) the proliferation and (B) the invasion of SGC-7901 cells via the JAK1/STAT3 pathway. ${ }^{*} \mathrm{P}<0.05$ vs. no treatment; ${ }^{\#} \mathrm{P}<0.05$ vs. IGF-1 alone. IGF-1, insulin-like growth factor-1; JAK1, Janus kinase 1; si-STAT3, short interfering RNA against STAT3.

survival of neurons in response to IGF-1 treatment has also been noted (36). The present study additionally demonstrated that IGF-1 treatment stimulated the phosphorylation of JAK1, STAT3 and IGF-1R in SGC-7901 cells, but not JAK2 or JAK3. 
An explanation for the inconsistencies between the present study and Gual et al (33) may be the different cell types employed. We hypothesize that JAK1 and STAT3 are associated with IGF-1-regulated signaling in SGC-7901 cells.

The present study demonstrated that treatment with the IGF-1R inhibitor NT157 reversed the elevated expression of MMP-11 and the phosphorylation of STAT3, JAK1 and IGF-1R as induced by IGF-1 in SGC-7901 cells. NT157 was previously demonstrated to affect IGF-1R and STAT3 in the inhibition of colorectal cancer development (37). Zong et al (38) demonstrated that STAT3, and not STAT5, was activated in response to IGF-1 in $293 \mathrm{~T}$ cells overexpressing IGF-1R, and that the IGF-1 stimulation of endogenous IGF-1R promoted the tyrosine phosphorylation of STAT3, JAK1 and 2. The specific mediation of STAT3 activation by insulin and IGF-1 receptors has previously been demonstrated (39). A recent study identified that the alterations in cellular behavior induced by IGF-1R and p38 mitogen-activated protein kinase inhibitors were accompanied by alterations to the level of STAT3 in human dental pulp stem cell quiescence, proliferation and differentiation, indicating that STAT3 may be a target for IGF-1R (40).

Quelle et al (41) demonstrated that STATs were direct targets for activated JAKs. Thus, the present study raised the question of the physiological role of JAK1 activation by IGF-1. Shimoda et al (42) reported that the role of JAK1 in STAT activation and receptor phosphorylation could be induced by granulocyte colony-stimulating factor, whereas Sawka-Verhelle et al (43) observed that insulin and IGF-1 caused STAT5B phosphorylation, and that JAKs were not associated with insulin-induced STAT5B activation in Cercopithecus aethiops Cos-7 kidney cells, whereas JAK2 was essential for the activation of STAT5B by growth hormones. The present study revealed that JAK1 and STAT3 were involved in regulating MMP-11 via IGF-1 in SGC-7901 cells. Previous studies have indicated that cell proliferation, invasion and metastasis in certain types of tumor require the involvement of the JAK/STAT pathway $(44,45)$. The JAK1/STAT3 pathway was implicated in the proliferation and invasion of SGC-7901 cells, and it can be inferred that the IGF-1-induced expression of MMP-11 promoted the proliferation and invasion of SGC-7901 cells through the JAK1/STAT3 pathway.

In summary, the results of the present study demonstrated that IGF-1 and MMP-11 expression is significantly upregulated in GC tissues, and that IGF-1 stimulates MMP-11 expression and the phosphorylation of STAT3, IGF-1R and JAK1 in SGC-7901 cells. Furthermore, the elevated expression of MMP-11, and the enhanced phosphorylation of STAT3, JAK1 and IGF-1R induced by IGF-1, are associated with IGF-1R in SGC-7901 cells. Based on these data, it can be concluded that IGF-1-induced MMP-11 expression induces the proliferation and invasion of SGC-7901 cells via the JAK1/STAT3 pathway.

\section{Acknowledgements}

Not applicable.

\section{Funding}

No funding was received.

\section{Availability of data and materials}

The analyzed data sets generated during the study are available from the corresponding author, on reasonable request.

\section{Authors' Contributions}

CS designed the project and reviewed the manuscript. WW conducted the experiments and drafted the manuscript. CW analyzed the data and drafted the manuscript.

\section{Ethics approval and consent to participate}

The present study was approved by the Institutional Research Ethics Committee of Renji Hospital. Written informed consent was obtained from all participants for the use of tissue samples.

\section{Consent for publication}

Study participants provided approval for publication.

\section{Competing interests}

The authors declare that they have no competing interests.

\section{References}

1. Ferro A, Peleteiro B, Malvezzi M, Bosetti C, Bertuccio P, Levi F, Negri E, La Vecchia C and Lunet N: Worldwide trends in gastric cancer mortality (1980-2011), with predictions to 2015 and incidence by subtype. Eur J Cancer 50: 1330-1344, 2014.

2. Ferlay J, Bray F, Pisani P and Parkin DM: Globocan 2000: Cancer Incidence, Mortality and Prevalence Worldwide. IARC Press, Lyon, 2001.

3. Velho S, Fernandes MS, Leite M, Figueiredo C and Seruca R: Causes and consequences of microsatellite instability in gastric carcinogenesis. World J Gastroenterol 20: 16433-16442, 2014.

4. Oue N, Aung PP, Mitani Y, Kuniyasu H, Nakayama H and Yasui W: Genes involved in invasion and metastasis of gastric cancer identified by array-based hybridization and serial analysis of gene expression. Oncology 69 (Suppl 1): S17-S22, 2005.

5. Li X, Zhang Y, Zhang H, Liu X, Gong T, Li M, Sun L, Ji G, Shi Y, Han Z, et al: miRNA-223 promotes gastric cancer invasion and metastasis by targeting tumor suppressor EPB41L3. Mol Cancer Res 9: 824-833, 2011.

6. Ganesan K, Ivanova T, Wu Y, Rajasegaran V, Wu J, Lee MH, Yu K, Rha SY, Chung HC, Ylstra B, et al: Inhibition of gastric cancer invasion and metastasis by PLA2G2A, a novel beta-catenin/TCF target gene. Cancer Res 68: 4277-4286, 2008

7. Dun B, Sharma A, Teng Y, Liu H, Purohit S, Xu H, Zeng L and She JX: Mycophenolic acid inhibits migration and invasion of gastric cancer cells via multiple molecular pathways. PLoS One 8: e81702, 2013

8. Wang L, Guo J, Wang Q, Zhou J, Xu C, Teng R, Chen Y, Wei Q and Liu ZP: LZTFL1 suppresses gastric cancer cell migration and invasion through regulating nuclear translocation of $\beta$-catenin. J Cancer Res Clin Oncol 140: 1997-2008, 2014.

9. Zhang ZZ, Shen ZY, Shen YY, Zhao EH, Wang M, Wang CJ, $\mathrm{CaO} \mathrm{H}$ and $\mathrm{Xu}$ J: HOTAIR long noncoding RNA promotes gastric cancer metastasis through suppression of poly $\mathrm{r}(\mathrm{C})$-binding protein (PCBP) 1. Mol Cancer Ther 14: 1162-1170, 2015.

10. Deryugina EI and Quigley JP: Matrix metalloproteinases and tumor metastasis. Cancer Metastasis Rev 25: 9-34, 2006.

11. Liu D, Nakano J, Ishikawa S, Yokomise H, Ueno M, Kadota K, Urushihara $M$ and Huang CL: Overexpression of matrix metalloproteinase-7 (MMP-7) correlates with tumor proliferation, and a poor prognosis in non-small cell lung cancer. Lung Cancer 58: 384-391, 2007. 
12. Kubben FJ, Sier CF, van Duijn W, Griffioen G, Hanemaaijer R, van de Velde CJ, van Krieken JH, Lamers CB and Verspaget HW: Matrix metalloproteinase-2 is a consistent prognostic factor in gastric cancer. Br J Cancer 94: 1035-1040, 2006.

13. Shim KN, Jung SA, Joo YH and Yoo K: Clinical significance of tissue levels of matrix metalloproteinases and tissue inhibitors of metalloproteinases in gastric cancer. J Gastroenterol 42: 120-128, 2007.

14. Łukaszewicz-Zając M, Mroczko B and Szmitkowski M: Gastric cancer-The role of matrix metalloproteinases in tumor progression. Clin Chim Acta 412: 1725-1730, 2011.

15. Zhao ZS, Chu YQ, YeZY, Wang YY and Tao HQ: Overexpression of matrix metalloproteinase 11 in human gastric carcinoma and its clinicopathologic significance. Hum Pathol 41: 686-696, 2010.

16. Kou YB,Zhang SY,Zhao BL, Ding R,Liu H and Li S: Knockdown of MMP11 inhibits proliferation and invasion of gastric cancer cells. Int J Immunopathol Pharmacol 26: 361-370, 2013.

17. Stewart CE and Rotwein P: Growth, differentiation, and survival: Multiple physiological functions for insulin-like growth factors. Physiol Rev 76: 1005-1026, 1996.

18. LeRoith D, Werner H, Beitner-Johnson D and Roberts CT Jr: Molecular and cellular aspects of the insulin-like growth factor I receptor. Endocr Rev 16: 143-163, 1995.

19. Delafontaine P, Song YH and Li Y: Expression, regulation, and function of IGF-1, IGF-1R, and IGF-1 binding proteins in blood vessels. Arterioscler Thromb Vasc Biol 24: 435-444, 2004.

20. Zhang Y, Moerkens M, Ramaiahgari S, de Bont H, Price L, Meerman $\mathbf{J}$ and van de Water B: Elevated insulin-like growth factor 1 receptor signaling induces antiestrogen resistance through the MAPK/ERK and PI3K/Akt signaling routes. Breast Cancer Res 13: R52, 2011.

21. Kang HJ, Yi YW, Kim HJ, Hong YB, Seong YS and Bae I: BRCA1 negatively regulates IGF-1 expression through an estrogen-responsive element-like site. Cell Death Dis 3: e336, 2012.

22. Li S, Lei X, Zhang J, Yang H, Liu J and Xu C: Insulin-like growth factor 1 promotes growth of gastric cancer by inhibiting foxol nuclear retention. Tumour Biol 36: 4519-4523, 2015.

23. Ge J, Chen Z, Huang J, Yuan W, Den Z and Chen Z: Silencing insulin-like growth factor-1 receptor expression inhibits gastric cancer cell proliferation and invasion. Mol Med Rep 11: 633-638, 2015.

24. Seoane A, Bessa X, Balleste B, O'Callaghan E, Panadès A, Alameda F, Navarro S, Gallén M, Andreu M and Bory F: Helicobacter pylori and gastric cancer: Relationship with histological subtype and tumor location. Gastroenterol Hepatol 28: 60-64, 2005 (In Spanish)

25. Ajani J, D'Amico TA, Hayman JA, Meropol NJ and Minsky B National Comprehensive Cancer Network: Gastric cancer. Clinical practice guidelines in oncology. J Natl Compr Canc Netw 1: 28-39, 2003.

26. Matsubara J, Yamada Y, Nakajima TE, Kato K, Hamaguchi T, Shirao K, Shimada Y and Shimoda T: Clinical significance of insulin-like growth factor type 1 receptor and epidermal growth factor receptor in patients with advanced gastric cancer. Oncology 74: 76-83, 2008.

27. Livak KJ and Schmittgen TD: Analysis of relative gene expression data using real-time quantitative PCR and the 2(-Delta Delta C(T)) method. Methods 25: 402-408, 2001

28. Kim JE, Lee MH, Nam DH, Song HK, Kang YS, Lee JE, Kim HW, Cha JJ, Hyun YY, Han SY, et al: Celastrol, an NF- $\kappa B$ inhibitor, improves insulin resistance and attenuates renal injury in db/db mice. PLoS One 8: e62068, 2013.

29. Zhang BG, Li JF, Yu BQ, Zhu ZG, Liu BY and Yan M: microRNA-21 promotes tumor proliferation and invasion in gastric cancer by targeting PTEN. Oncol Rep 27: 1019-1026, 2012

30. Vignais ML, Sadowski HB, Watling D, Rogers NC and Gilman M: Platelet-derived growth factor induces phosphorylation of multiple JAK family kinases and STAT proteins. Mol Cell Biol 16: 1759-1769, 1996.
31. Giorgetti-Peraldi S, Peyrade F, Baron V and Van Obberghen E Involvement of Janus kinases in the insulin signaling pathway. Eur J Biochem 234: 656-660, 1995.

32. Saad MJ, Carvalho CR, Thirone AC and Velloso LA: Insulin induces tyrosine phosphorylation of JAK2 in insulin-sensitive tissues of the intact rat. J Biol Chem 271: 22100-22104, 1996.

33. Gual P, Baron V, Lequoy V and Van Obberghen E: Interaction of Janus kinases JAK-1 and JAK-2 with the insulin receptor and the insulin-like growth factor-1 receptor. Endocrinology 139 : 884-893, 1998 .

34. Chen J, Sadowski HB, Kohanski RA and Wang LH: Stat5 is a physiological substrate of the insulin receptor. Proc Natl Acad Sci USA 94: 2295-2300, 1997.

35. Sawka-Verhelle D, Filloux C, Tartare-Deckert S, Mothe I and Van Obberghen E: Identification of Stat $5 \mathrm{~B}$ as a substrate of the insulin receptor. Eur J Biochem 250: 411-417, 1997.

36. Yadav A, Kalita A, Dhillon S and Banerjee K: JAK/STAT3 pathway is involved in survival of neurons in response to insulin-like growth factor and negatively regulated by suppressor of cytokine signaling-3. J Biol Chem 280: 31830-31840, 2005.

37. Sanchez-Lopez E, Flashner-Abramson E, Shalapour S, Zhong Z, Taniguchi K, Levitzki A and Karin M: Targeting colorectal cancer via its microenvironment by inhibiting IGF-1 receptor-insulin receptor substrate and STAT3 signaling. Oncogene 35: 2634-2644, 2016

38. Zong CS, Chan J, Levy DE, Horvath C, Sadowski HB and Wang LH: Mechanism of STAT3 activation by insulin-like growth factor I receptor. J Biol Chem 275: 15099-15105, 2000.

39. Zhang W, Zong CS, Hermanto U, Lopez-Bergami P, Ronai Z and Wang LH: RACK1 recruits STAT3 specifically to insulin and insulin-like growth factor 1 receptors for activation, which is important for regulating anchorage-independent growth. Mol Cell Biol 26: 413-424, 2006.

40. Vandomme J, Touil Y, Ostyn P, Olejnik C, Flamenco P, El Machhour R, Segard P, Masselot B, Bailliez Y, Formstecher P and Polakowska R: Insulin-like growth factor 1 receptor and p38 mitogen-activated protein kinase signals inversely regulate signal transducer and activator of transcription 3 activity to control human dental pulp stem cell quiescence, propagation, and differentiation. Stem Cells Dev 23: 839-851, 2014.

41. Quelle FW, Thierfelder W, Witthuhn BA, Tang B, Cohen S and Ihle JN: Phosphorylation and activation of the DNA binding activity of enriched Statl by the Janus protein-tyrosine kinases and the epidermal growth factor receptor. J Biol Chem 270: 20775-20780, 1995.

42. Shimoda K, Feng J, Murakami H, Nagata S, Watling D, Rogers NC, Stark GR, Kerr IM and Ihle JN: Jak1 plays an essential role for receptor phosphorylation and Stat activation in response to granulocyte colony-stimulating factor. Blood 90: 597-604, 1997.

43. Sawka-Verhelle D, Tartare-Deckert S, Decaux JF, Girard J and Van Obberghen E: Stat $5 \mathrm{~B}$, activated by insulin in a Jak-independent fashion, plays a role in glucokinase gene transcription. Endocrinology 141: 1977-1988, 2000.

44. Macha MA, Satyanarayana R, Suprit G, Pai P, Ponnusamy MP, Batra SK and Jain M: Guggulsterone decreases proliferation and metastatic behavior of pancreatic cancer cells by modulating JAK/STAT and Src/FAK signaling. Cancer Lett 341: 166-177, 2013.

45. Kowshik J, Baba AB, Giri H, Deepak Reddy G, Dixit M and Nagini S: Astaxanthin inhibits JAK/STAT-3 signaling to abrogate cell proliferation, invasion and angiogenesis in a hamster model of oral cancer. PLoS One 9: e109114, 2014.

This work is licensed under a Creative Commons Attribution-NonCommercial-NoDerivatives 4.0 International (CC BY-NC-ND 4.0) License. 